\title{
TITLE:
}

\section{Photoluminescence of porous silicon exposed to ambient air}

$\operatorname{AUTHOR}(S)$ :

MARUYAMA, T; OHTANI, S

\section{CITATION:}

MARUYAMA, T ... [et al]. Photoluminescence of porous silicon exposed to ambient air. APPLIED PHYSICS LETTERS 1994, 65(11): 1346-1348

\section{ISSUE DATE:}

1994-09-12

URL:

http://hdl.handle.net/2433/43529

\section{RIGHT:}

Copyright 1994 American Institute of Physics. This article may be downloaded for personal use only. Any other use requires prior permission of the author and the American Institute of Physics. 


\section{Photoluminescence of porous silicon exposed to ambient air}

Toshiro Maruyama and Satoshi Ohtani

Department of Chemical Engineering, Faculty of Engineering, Kyoto University, Kyoto 606, Japan

(Received 18 April 1994; accepted for publication 7 July 1994)

The room-temperature photoluminescence and structure were studied concerning porous silicon which was exposed to ambient air. Water vapor in ambient air gradually oxidized the surface of the porous silicon with developing $\mathrm{Si}-\mathrm{O}-\mathrm{Si}$ bonds. This room-temperature oxidation progressively replaced an unstable $\mathrm{H}$-passivated surface with a more stable O-passivated surface, dramatically increasing the intensity of the photoluminescence.

Since Canham ${ }^{1}$ reported room-temperature visible luminescent porous silicon (Si), much research has been performed on porous $\mathrm{Si}$, which was treated by various oxidation techniques to stabilize the photoluminescence (PL) of the as-anodized porous $\mathrm{Si}$. However, there are few reports on the stability of as-anodized porous Si. Canham et al. ${ }^{2}$ studied low-temperature ( $4.2 \mathrm{~K}) \mathrm{PL}$ and chemical composition during ambient air exposure. They reported that the 10 week storage of as-anodized $p^{-}(30-50 \Omega \mathrm{cm})$ porous $\mathrm{Si}$ and 6 month storage of as-anodized $\mathrm{P}^{+}(0.01-0.04 \Omega \mathrm{cm})$ porous Si brought about blue shifts and drops in intensity of PL.

This lctter shows the room-tempcrature $\mathrm{PL}$ of porous $\mathrm{Si}$ which is exposed to ambient air for several weeks. The structure of the porous $\mathrm{Si}$ is discussed on the basis of the measurements of infrared reflection spectra and x-ray photoelectron spectroscopy.

The porous Si layers were formed on a $p$-type $\mathrm{Si}(100)$ wafer (Shin-Etsu Chemical Co., Ltd.) of resistivity 8-12 $\Omega \mathrm{cm}$. Aluminum films were sputtered on the backs of wafers to improve the uniformity of the anodic current. Anodizalion was carried out using $30 \mathrm{~mA} \mathrm{~cm}^{-2}$ in a solution of $\mathrm{HF}, \mathrm{H}_{2} \mathrm{O}$, and $\mathrm{C}_{2} \mathrm{H}_{5} \mathrm{OH}$ (HF: $\mathrm{H}_{2} \mathrm{O}: \mathrm{C}_{2} \mathrm{H}_{5} \mathrm{OH}=1: 1: 2$ in weight). After 5 min anodization, the samples were dried in air with or without water rinse. For the exposition to dry air, the as-anodized sample was set in a desiccator. For exposition to humid air, the as-anodized sample was hung in open top vessels with a pool of water at the bottom. All samples were stored at room temperature.

The PL was measured at room temperature by means of a spectrofluorophotometer (Shimadzu RF-5000). The wavelength of the input power was $325 \mathrm{~nm}$. The infrared reflection spectra were obtained by means of a Fourier transform infrared spectrometer (Shimadzu FTIR-4300). The binding energy of silicon was measured by $\mathrm{x}$-ray photoelectron spectroscopy (XPS). The thickness of the porous Si layer was measured by the scanning electron micrograph.

The porous Si layers of $2 \mu \mathrm{m}$ thickness were obtained. The as-anodized porous $\mathrm{Si}$ with and without water rinse originally showed very weak reddish orange PL, but after prolonged exposure to air for several weeks the samples exhibited intense reddish orange PL to the naked eye under 325 $\mathrm{nm}$ ultraviolet light exposure. Figures 1(a) and 1(b) show changes in PL spectra of the porous Si which was kept in air without or with water rinse. In each figure, the PL of asprepared film is very weak, but the intensity significantly increases with extending exposure to air. Some difference in the spectra can be seen between porous Si with and without water rinse. The porous $\mathrm{Si}$ without water rinse shows changes in peak wavelength from 660 to $600 \mathrm{~nm}$ after two weeks. That is, the $600 \mathrm{~nm}$ peak becomes larger than the 660 $\mathrm{nm}$ peak. The porous Si with water rinse shows that the spectrum keeps the similar shape. The intensity increases slowly in its initial stage but the increase is accelerated with extending exposure time.

Figures 2(a) and 2(b) show the corresponding changes in the infrared reflection spectrum of the porous Si. Absorption peaks at about 2090,2120, 2140,910,650, and $640 \mathrm{~cm}^{-1}$ represent $\mathrm{Si}-\mathrm{H}, \mathrm{Si}-\mathrm{H}_{2}, \mathrm{Si}-\mathrm{H}_{3}$ stretching modes, $\mathrm{Si}-\mathrm{H}_{2}$ scissor mode, $\mathrm{Si}-\mathrm{H}_{n}$ deformation mode, and $\mathrm{Si}-\mathrm{H}$ bending mode,
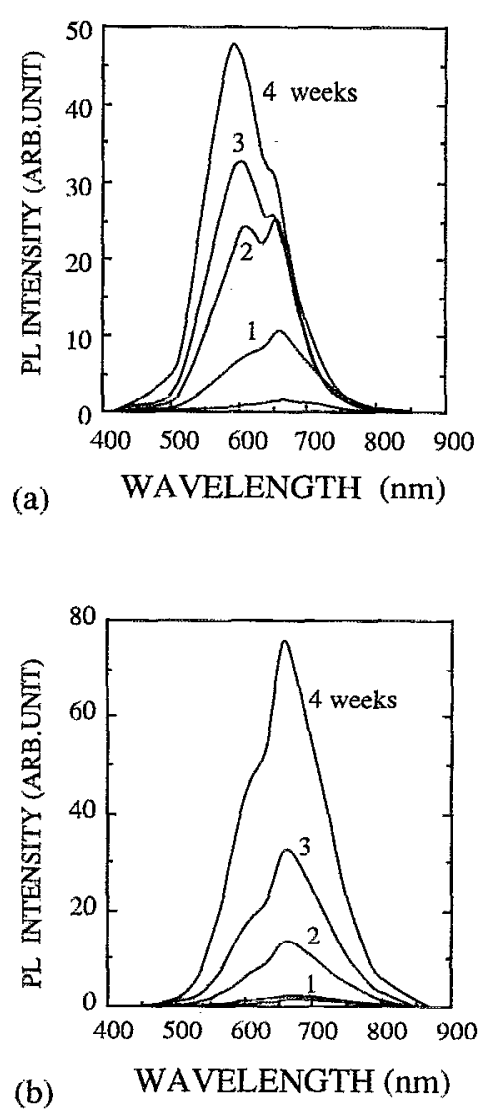

FIG. 1. Photoluminescence spectra of the porous Si which were kept in air (a) without water rinse and (b) with water rinse. 

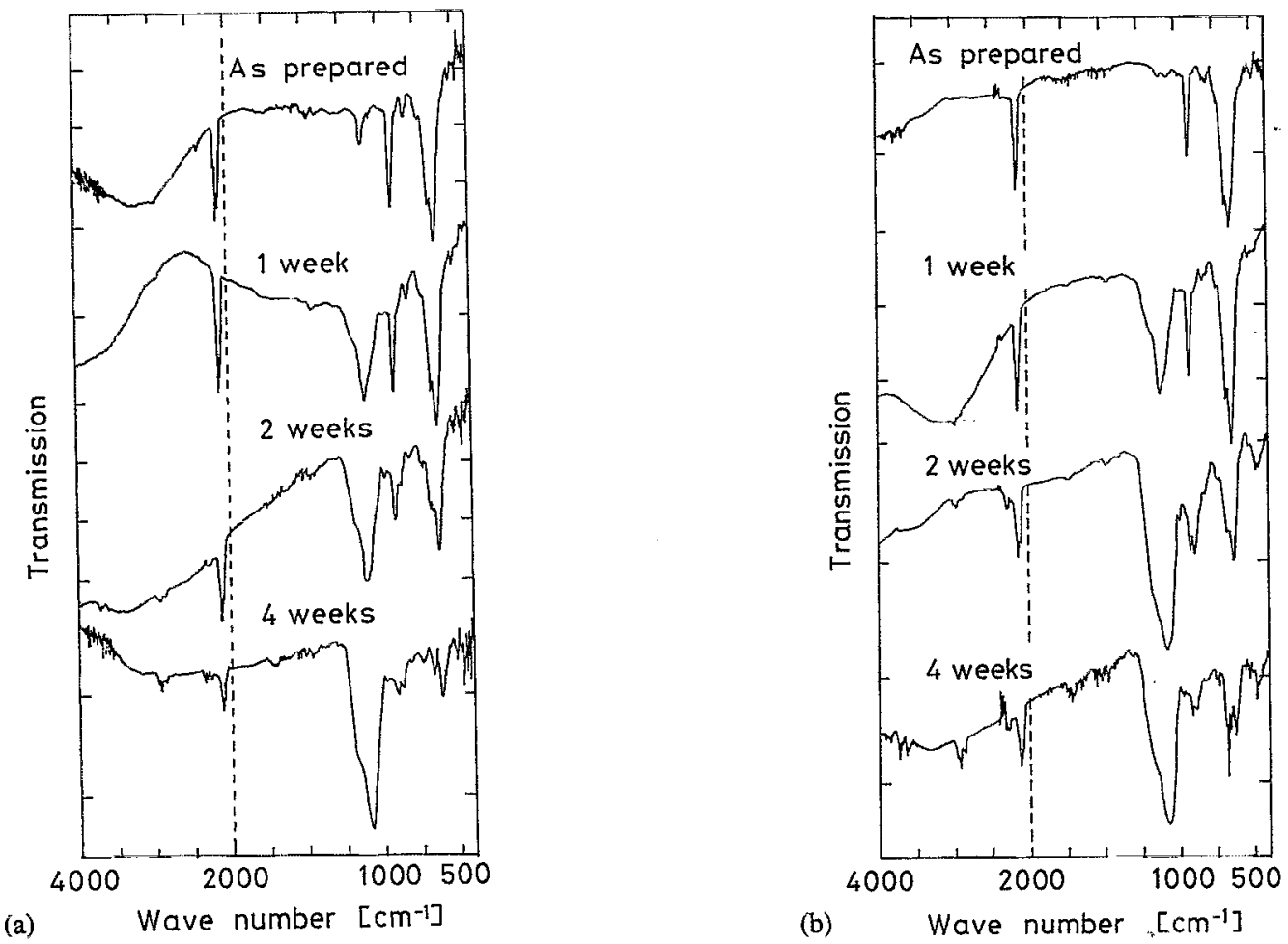

FTG. 2. Infrared reflection spectrum of the porous Si which was kept in air (a) without water rinse and (b) with water rinse.
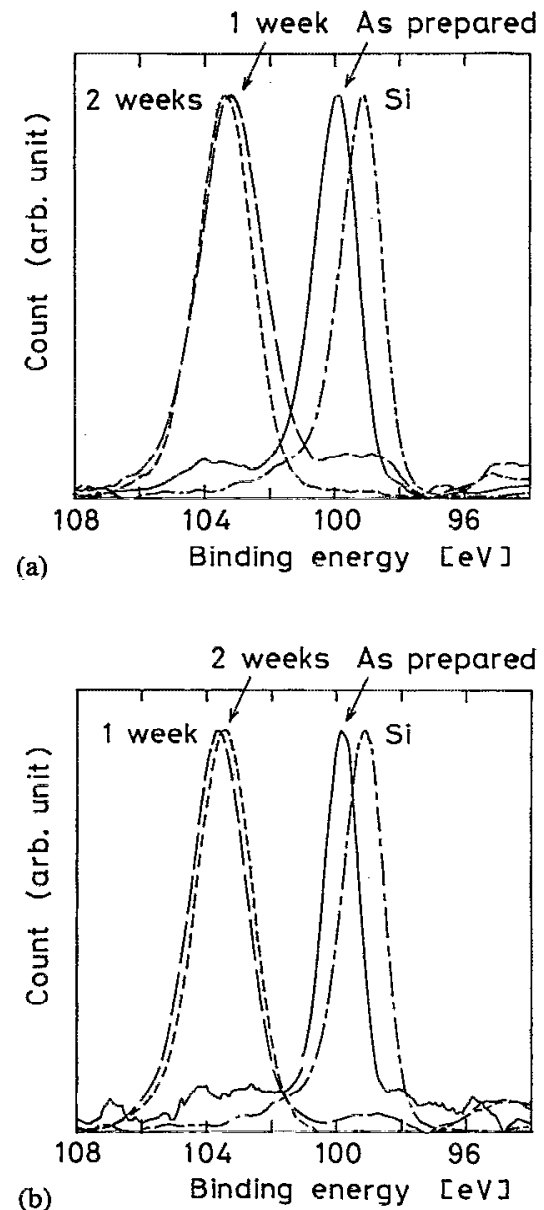

FIG. 3. XPS spectra of the Si $2 p$ of the porous $\mathrm{Si}$ which was kept in air (a) without water rinse and (b) with water rinse. respectively. Thus the tangling bonds at the wall of the pore which was generated in anodic reaction were terminated by the hydrogen generated in the reaction. During ambient exposure, however, additional absorption peaks appear in infrared reflection spectra for the films, suggesting a dramatic change in structure with time. Absorption peaks at about 1080 and $460 \mathrm{~cm}^{-1}$ represent the Si-O-Si stretching mode and $\mathrm{Si}-\mathrm{O}-\mathrm{Si}$ bending mode. The increase in the $\mathrm{Si}-\mathrm{O}-\mathrm{Si}$ bond is ascribed to a gradual room-temperature oxidation of the porous Si skeleton.

Figures 3(a) and 3(b) show the XPS spcctra of the Si $2 p$ of the porous Si. For comparison, the XPS spectrum for single crystalline silicon is also shown in these figures. After 1 week exposure, the peak position shifts from 99.8 to 103.6 $\mathrm{eV}$ for $\mathrm{Si}(\mathrm{IV})$. Thus the unstable $\mathrm{H}$-passivated surface is pro-

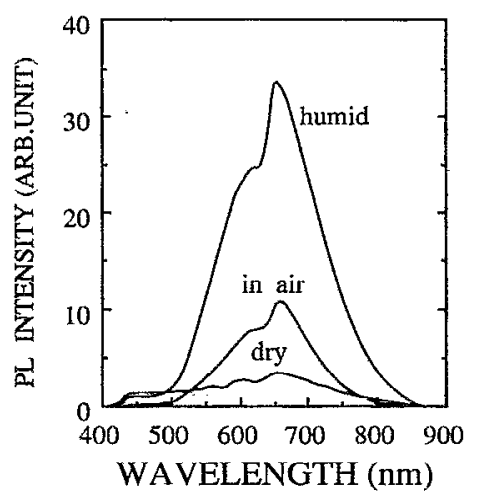

FIG. 4. Photoluminescence spectra for the porous Si which were kept in dry or humid air for a week without water rinse. 
gressively replaced with the more stable $\mathrm{O}$-passivated surface while increasing the PL intensity. This change in structure with exposure time is inferred to be associated with the increase in PL with exposure time. The formation of silicon oxide barrier greatly reduces the photoexcited carrier tunneling between $\mathrm{Si}$ microcrystallites. This may be the most straightforward way to exclude recombination due to tunneling. ${ }^{3}$

The effect of water vapor in ambient air is discussed on the basis of the measurements for the porous Si which was exposed to the air with artificial humidity. Figures 4 and 5 show the PL spectra and the corresponding infrared reflection spectra for the porous Si after storage at room temperature for a week under two extreme conditions: (1) dry air, or (2) humid air. Also shown in Fig. 4 is the PL spectrum for porous Si exposed to ambient air. The porous Si stored in dry air keeps the same intensity of $\mathrm{PL}$ as that for as-prepared one (see Fig. 1). The infrared reflection spectra in Fig. 5 show no change in surface structure from that for as-prepared one (see Fig. 2). On the other hand, the porous Si exposed to humid air shows a large increase in the intensity of PL, which is comparable to that exposed to ambient air for three weeks (see Fig. 1). The infrared reflection spectra in Fig. 5 show that the large absorption based on the $\mathrm{Si}-\mathrm{O}-\mathrm{Si}$ bond $(1070$ $\mathrm{cm}^{-1}$ ) appears with an absorption based on $\mathrm{Si}-\mathrm{OH}$ bond $\left(950,1070\right.$, and $\left.3310 \mathrm{~cm}^{-1}\right)$. Thus, humidity in air enhances the $\mathrm{PL}$ intensity, developing $\mathrm{Si}-\mathrm{O}-\mathrm{Si}$ bonds in porous $\mathrm{Si}$. The room-temperature oxidation of porous $\mathrm{Si}$ is expected to proceed in a spatially inhomogeneous manner as suggested by Grundner and Jacob. ${ }^{4}$ Initially the formation of a Si-OH group occurs via the hydrolysis of $\mathrm{Si}-\mathrm{F}$ groups by $\mathrm{H}_{2} \mathrm{O}$ from the atmosphere. Once a $\mathrm{Si}-\mathrm{OH}$ group has formed it acts as a preferential adsorption site for water molecules. Condensation of neighboring $\mathrm{Si}-\mathrm{OH}$ groups gives rise to internal $\mathrm{Si}$ O-Si bridges. ${ }^{2}$

In conclusion, the room-temperature photoluminescence and structure of porous silicon which was exposed to ambient air were studied. Water vapor in ambient air gradually

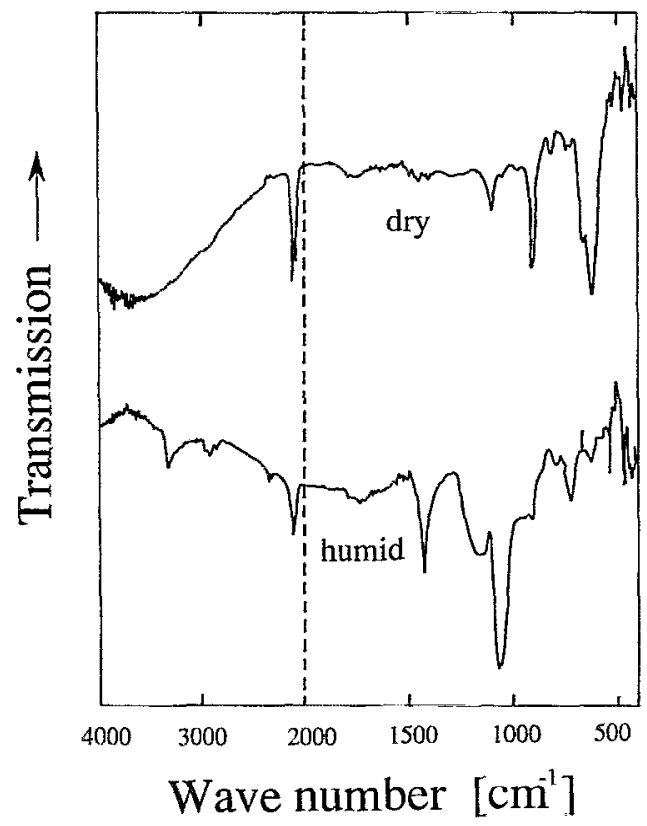

FIG. 5. Infrared refiection spectrum for the porous Si which were kept in dry or humid air for a week without water rinse.

oxidized the surface of porous silicon with developing $\mathrm{Si}-\mathrm{O}-\mathrm{Si}$ bonds. This room-temperature oxidation progressively replaced an unstable $\mathrm{H}$-passivated surface with a more stable O-passivated surface, dramatically increasing the intensity of the photoluminescence.

This work was supported by the Ookura Foundation.

${ }^{1}$ L. T. Canham, Appl. Phys. Lett. 57, 1046 (1990).

${ }^{2}$ L. T. Canham, M. R. Houlton, W. Y. Leong, C. Pickering, and J. M. Keen, J. Appl. Phys. 70, 422 (1991).

${ }^{3}$ J. C. Vial, A. Bsiesy, F. Gaspard, R. Hérino, M. Ligeon, F. Muller, R. Romestain, and R. M. Macfarlane, Phys. Rev. B 45, 14171 (1992).

${ }^{4}$ M. Grundner and H. Jacob, Appl. Phys. A 39, 73 (1986). 